Article

\title{
Carbon-Neutral-Campus Building: Design Versus Retrofitting of Two University Zero Energy Buildings in Europe and in the United States
}

\author{
Adriana Del Borghi ${ }^{1, *}$, , Thomas Spiegelhalter ${ }^{2}$, Luca Moreschi ${ }^{1}$ and Michela Gallo ${ }^{1}$ \\ 1 Department of Civil Chemical and Environmental Engineering, DICCA, University of Genoa, \\ Via Montallegro 1, 16145 Genova, Italy; luca.moreschi@edu.unige.it (L.M.); michela.gallo@unige.it (M.G.) \\ 2 Miami Beach Urban Studios, College of Architecture and the Arts, Florida International University, \\ Miami, FL 33139, USA; thomas.spiegelhalter@fiu.edu \\ * Correspondence: adriana.delborghi@unige.it
}

Citation: Del Borghi, A.;

Spiegelhalter, T.; Moreschi, L.; Gallo, M. Carbon-Neutral-Campus Building: Design Versus Retrofitting of Two University Zero Energy Buildings in Europe and in the United States. Sustainability 2021, 13, 9023. https://doi.org/10.3390/su13169023

Academic Editor: Bahadori-Jahromi, A.

Received: 18 June 2021

Accepted: 4 August 2021

Published: 12 August 2021

Publisher's Note: MDPI stays neutral with regard to jurisdictional claims in published maps and institutional affiliations.

Copyright: (c) 2021 by the authors. Licensee MDPI, Basel, Switzerland. This article is an open access article distributed under the terms and conditions of the Creative Commons Attribution (CC BY) license (https:// creativecommons.org/licenses/by/ $4.0 /)$.

\begin{abstract}
Carbon-neutral design is pivotal for achieving the future energy performance targets of buildings. This paper shows research projects that promote the environmental sustainability of university campuses at the international level. GHG accounting methods and operational strategies adopted by the University of Genoa (UNIGE), Italy, and the Florida International University (FIU) in Miami, USA, are compared, with both universities striving to make buildings and campus facilities benchmarked and carbon neutral in the near future. Our comparative research includes analyzing campus buildings at both universities and their attempts to design, retrofit, and transform these buildings into carbon neutral buildings. Two case studies were discussed: the Smart Energy Building (SEB) in the Savona Campus of the UNIGE, and the Paul L. Cejas School of Architecture (PCA) Building of the FIU. The SEB's construction reduced emissions by about $86 \mathrm{tCO}_{2} / \mathrm{y}$, whereas the PCA's retrofitting reduced GHG emissions by $30 \%$. Other operational strategies, including energy efficiency and energy generation, allowed the UNIGE to reduce their overall Scope $1+2$ GHG emissions by $25 \%$ from 2013 to 2016 . Globally, FIU Scope $1+2$ GHG emissions per person were found to result in more than three times the UNIGE's emissions, and 2.4 times if evaluated per square meter. The results were compared with GHG emissions and operational strategies from other universities.
\end{abstract}

Keywords: carbon neutral; energy; retrofitting; building information modeling; campus benchmarking; university

\section{Introduction}

One of the most significant challenges of improving sustainability at the global level is the management of climate change and the reduction of greenhouse gas emissions. According to the International Energy Agency (IEA), energy efficiency measures represent the main strategies and targets of any country's plans to combat the climate crisis. Despite energy efficiency being one of the most economically viable solutions and showing a great synergy with the use of renewable energy sources-another key measure-while also presenting several social co-benefits, such as job creation and comfort, the last IEA report on energy efficiency highlighted gradual reductions in the rates of efficiency improvement and investment in the last few years [1]. At the same time, the IEA has set targets and opportunities for the world to meet ambitious climate global goals, such as constructing or repairing buildings in order to reduce or even reach net zero in their energy demands while improving building comfort and redesigning industrial processes in general. To meet the climate and energy efficiency targets, policy-makers need to make significant decisions and planning solutions in order to fully exploit these potential measures [2]. For the building sector, examples of these measures are the large-scale deployment of nearly (or net) zero-energy buildings (nZEBs) and zero-carbon buildings (ZCBs), or carbon-neutral 
buildings (CNBs). nZEBs combine energy efficiency and renewable energy generation to balance weighted energy demand and supply over a specified time period. In ZCBs/CNBs, the annual balance of carbon emissions from all energy use would be net-zero [3].

From the analysis of policy activities implemented to promote zero-energy buildings in the EU and US, it is clear that very little progress has been made in adopting zeroenergy or climate-neutral policies. Moreover, there is a lack of knowledge regarding the market uptake of ZEBs and ZCBs/CNBs, and in particular for non-residential and existing buildings. Nevertheless, a high percentage of energy is used in non-residential buildings, including schools, hospitals, and administrative offices, accounting for an average of $25 \%$ in terms of energy consumption and corresponding greenhouse gases (GHG) of the global building stock. Among them, the educational sector accounts for $17 \%$, showing a $1.1 \%$ increase in energy consumption rates per year due to the growing number of new technological appliances, such as IT devices and new telecommunication and air conditioning systems [4].

Within the educational sector, university campus buildings represent a challenge to the broadening of non-residential energy and climate targets. Firstly, the qualities of these buildings and the processes required to create them can encourage student learning, create healthy, high-performance learning environments and demonstrate environmental leadership in minimizing the impact of the built environment. Then, reducing and controlling the operating costs of buildings, particularly energy and maintenance costs, is highly attractive, especially for public university campuses often characterized by challenging annual budgets and constantly rising energy costs [5].

It is crucial to understand the key role played by universities through "Campus as a Living Lab" (CLL) projects, especially in the field of climate action, not only in terms of strategy definition but also in evaluations of progress made. The University of British Columbia set the ambitious target of becoming carbon neutral by 2050 and is experimenting with different strategies in order to meet this goal. Its CLL program has been analyzed in order to allow better and faster replicability by other universities [6]. Despite energy efficiency measures always needing to be sought, carbon neutrality of campus buildings can be achieved not only by GHG emission reductions but also by the application of carbon sinks. In 2020, the University of Michigan developed a scalable approach to estimate carbon storage and bio-sequestration of university landholdings through remote sensing [7]. However, for the transition towards carbon neutral campuses to be sustainable, not only do environmental targets have to be set, but also the campuses' economic viability should be tested and verified. The University of Dayton has identified the economic investment needed to achieve campus carbon neutrality by applying four different measures, and their life-cycle cost analysis highlighted the reasonableness of the investment, especially if the social cost of carbon is internalized within their budgeting [8].

To reach these climate goals and to prevent incorrect decisions, it is clear that goal indicators that are immediately comprehensible and defined in relation to robust and objective quantitative metrics should be used, and carbon neutrality, in particular, must be accounted for in a reliable and verifiable way. Thus far, the basic elements of the curricular design process with integrated project delivery measures for a comprehensive Net-Zero-Design regulatory framework are either incomplete or missing in most accredited architectural schools and in the professions of the US [9]. Focusing on carbon neutrality, some research has been published on the impacts of university campuses, and GHG inventories have been developed to evaluate campus emissions worldwide [10-14]. Although the methodologies and results of these studies are different, it can be generally said that a medium-size university building has an average emission factor of 4000 tons of $\mathrm{CO}_{2 \text {-eq }}$ /year [10], mainly due to the fact that a majority of university buildings operate as energy hogs [15]. This means that while there are many opportunities to improve their sustainability and cut down on their emissions, achieving at the same time a good example of loads, there is a strong need for harmonization for solid cross-country comparisons and tracking transitions to ZEBs. Although, thus far, a conventional methodology for assessing, evaluating, and re- 
porting the GHG emissions of university campuses does not exist, there is a consensus that GHG accounting shall be performed in a comprehensive global standardized framework. According to this goal, some Italian universities have started to define common sources for the definition of relevant emission factors in order to improve comparability among campuses [16]. GHG Protocol [17], ISO 14064 international standard [18], and carbon footprint, a methodology based on Life Cycle Assessment [19], are example methodologies used to quantify GHG at an international level [20].

In the present paper, the accounting of GHG emissions and removals of the University of Genoa (UNIGE), Italy, and the Florida International University (FIU) in Miami, USA, is presented. FIU accounted its GHG emissions according to the GHG Protocol [17], while the GHG inventory of UNIGE was accounted by the authors in accordance with the international standard ISO 14064 [18], revised in 2019. Detailed information on data collecting methods and sources for both universities is shown in the paper with the aim of improving reliable greenhouse gas accounting and promoting environmental sustainability of University campuses operation at an international level. The obtained GHG results were normalized to the surface of buildings $\left(\mathrm{m}^{2}\right)$ and to the University population (faculty, staff, student), obtaining useful benchmark indicators to enhance the comparison and transferring of findings to other universities. Furthermore, two case studies were presented, the Smart Energy Building in the Savona Campus of UNIGE and the Paul L. Cejas School of Architecture Building of FIU-respectively designed and retrofitted into a ZEB-to show GHG emission reduction potential for different operational strategies at University level, including energy efficiency and energy generation, aiming at reducing campuses GHG emissions on the pathway to make buildings and campus facilities benchmarked and carbon-neutral in the near future.

\section{Materials and Methods}

\subsection{Zero-Energy Buildings Legislation in the European Union and United States}

European legislation on the energy performance of buildings - the European Union (EU) Energy Performance of Buildings Directive (EPBD) [21]—set "nearly-zero-energy buildings" as a standard for new buildings by the end of 2020, whereas the United States (US) is aiming at "net-zero-energy buildings". Even if the two different terms suggest similar concepts, significant differences can be found in the definitions so that the real global progress toward ultra-low energy buildings is difficult to analyze and check [22]. The EPBD, the Energy-Efficiency Directive (EED) [23], the directive on renewable energy sources [24], and directives on ecodesign and energy labeling $[25,26]$ give the legal framework for the EU's ZEB target. The European Green Deal, the strategy aiming at transforming the EU into a modern, resource-efficient, and competitive economy where there are no net emissions of greenhouse gases by 2050, include, among others, the need for decarbonization of the energy sector and ensuring higher energy efficiency of buildings [27]. To reach these targets, EU countries had to write-up and submit national plans for a transition towards nearly zero-energy buildings, describing how they planned to increase the number of nZEBs in their country to be compliant with the directive. To monitor the progress of plans execution, the European Commission requested - and received in 2019-a comprehensive analysis of building energy renovation measures and activities and the spread of nearly zero-energy buildings in the EU [28]. According to this report, the weighted energy renovation rate was calculated to be about $1 \%$. If this rate continues in forthcoming years, the building sector will definitely fail to meet its required contribution to the overall reduction of primary energy demand and the consequent reduction in greenhouse gas emissions. The European Nearly Zero-Energy Building Strategy 2020 (ZEBRA2020) [29], with a coverage of 17 European countries and about $89 \%$ of the European building stock and population, monitored the market spread of nZEBs across Europe and provided data on how to reach the nZEB standard.

In the United States, the Department of Energy (DOE) has set by 2025 the ambitious target of defining the technology and knowledge base for cost-effective zero-energy com- 
mercial buildings and has stated the goal through the federal Energy Independence and Security Act of 2007 and Executive Order 13514 [30]. This Order has been signed in October 2009 and requires all new Federal buildings that are entering the planning process in 2020 or thereafter to be designed to achieve zero-net-energy by 2030. In 2014, DOE Building Technologies Office contracted with the National Institute of Building Sciences (NIBS) for the establishment of standard definitions, associated nomenclature, and measurement guidelines for zero energy buildings. This cooperation is aimed at achieving widespread adoption and use by the building industry [31]. According to the document, despite recognizing that the terms net-zero energy (NZE) and zero-net energy (ZNE) are in wide use and convey the same meaning as zero energy, DOE and NIBS selected the term Zero Energy Building (ZEB) for "an energy-efficient building where, on a source energy basis, the actual annual delivered energy is less than or equal to the onsite renewable exported energy". Therefore, looking for simplicity, consistency, and focusing on the core goal, in this paper we will use the term ZEB.

Nevertheless, it must be noted that EU and US legislation still shows few differences in the practical evaluation of ZEBs (Table 1) [22]. The most relevant difference lies in the definition of the energy metric for the accounting of the net balance: the EU usually refers to the primary energy metric - the total amount of raw energy resources required for building operation - whereas the US applies the site energy metric - the amount of heat and electricity directly consumed by the building. Both EU and US apply similar end uses and life cycle stages, also not including the embodied energy of the building in the accounting of the energy net balance. Unlike the EU, the US instead considers the contribution of plug loads.

Table 1. Comparison of ZEB legislations in EU and US.

\begin{tabular}{|c|c|c|}
\hline \multirow{2}{*}{ Characteristic } & \multicolumn{2}{|c|}{ ZEB Legislation } \\
\hline & EU & US \\
\hline Metric & Primary (Source) energy & Final (Site) energy \\
\hline End uses and life-cycle stages included: & & \\
\hline heating, ventilation, and air conditioning & Yes & Yes \\
\hline Domestic hot water & Yes & Yes \\
\hline Lighting & Yes & Yes \\
\hline Plug load & No & Yes \\
\hline Embodied energy & No & No \\
\hline Minimum requirements & Both on energy efficiency and renewable energy & Only on energy efficiency \\
\hline Target buildings & Both new and existing buildings & Only new buildings \\
\hline
\end{tabular}

\subsection{Greenhouse Gas Accounting}

\subsubsection{Methodology}

The analysis of campus buildings at UNIGE and FIU were performed according to international standards, with the aim of diagnosing, retrofitting, and transforming them to carbon neutral operated buildings.

Besides calculating their inventories and quantifying the contribution of energy consumption to the overall university GHG emissions, both UNIGE and FIU developed strategies to reduce the environmental impacts of their buildings, resulting in being the major contributors due to their high energy consumption. To reach this goal, UNIGE designed a new ZEB, the so-called Smart Energy Building (SEB) within its Campus in Savona, while FIU retrofitted the Paul L. Cejas Architecture College (PCA) of FIU in Miami into a ZEB. While the SEB of UNIGE, Campus of Savona, is a new building designed to be a ZEB, the PCA College of FIU in Miami was retrofitted into a ZEB. The two case studies are presented in the following to show operational strategies, including energy efficiency and energy generation, towards the carbon-neutrality of university buildings.

The accounting of GHG emissions and removals of UNIGE was performed according to the ISO 14064:2006-I [18] standard, while FIU uses the Campus Carbon Calculator ${ }^{\mathrm{TM}}$ (CCC), hosted by the University of New Hampshire Sustainability Institute [32], which 
uses standard methodologies codified by the GHG Protocol Initiative [17]. Both ISO and GHG Protocol standards specify the principles and requirements for the quantification and reporting of GHG emissions and removals at the organization level. Conforming to these standards, GHG emissions were divided into the following categories: sources of GHG emissions under the direct control of the organization; indirect GHG emissions from consumption of purchased energy; other indirect emissions (university activities community emissions). For the aim of the present analysis, the two standards are comparable. According to the GHG Protocol, Indirect GHG emissions from consumption of purchased energy are limited to electricity, heat/cool, or steam, while the ISO standard also adds the 'fossil fuel-derived energy products' to the indirect Energy. These would be the same in the majority of cases, such as for this case study.

The methodology for GHG accounting includes the following steps:

1. Definition of the organizational and operational boundaries;

2. Development of the inventory by identifying all emission contributions;

3. Quantification of emissions and greenhouse gas removals;

4. Preparation of the report on GHG emissions.

The methodology used to determine organizational boundaries was the operational control approach. The GHGs considered were carbon dioxide $\left(\mathrm{CO}_{2}\right)$, methane $\left(\mathrm{CH}_{4}\right)$, nitrous oxide $\left(\mathrm{N}_{2} \mathrm{O}\right)$, sulfur hexafluoride $\left(\mathrm{SF}_{6}\right)$, perfluorocarbons (PFCs), and hydrofluorocarbons (HFCs) [17]. The GHG emissions were calculated using specific emission factors (EFs) retrieved from the Ecoinvent 3.1 [33] database or literature. The Ecoinvent database contains a wide range of raw materials, referring to both production processes and distribution phases. The IPCC 2013 [34] method was applied to determine the emission factors for the Global Warming Potential (GWP), i.e., the emission of carbon dioxide equivalent $\left(\mathrm{kgCO}_{2 \text {-eq }}\right.$ or $\left.\mathrm{tCO}_{2 \text {-eq }}\right)$ per unit of material/process. Thereafter, the GHG emissions generated by each material/process were calculated by multiplying the specific data collected for the corresponding emission factor.

Table 2 summarizes the approaches for GHG emissions accounting for both universities, while GHG emissions and removals are listed in Table 3.

Table 2. GHGs accounting approaches.

\begin{tabular}{|c|c|c|c|}
\hline & & UNIGE & FIU \\
\hline \multirow{7}{*}{ GHG inventory } & $\begin{array}{l}\text { Institution in charge of the } \\
\text { accounting }\end{array}$ & $\begin{array}{c}\text { University Commission on } \\
\text { Environmental Sustainability }\end{array}$ & Office of University Sustainability \\
\hline & Baseline year & 2013 & 2009 \\
\hline & Last annual progress evaluation & 2016 & 2016 \\
\hline & Standard & ISO 14064:2016-I & GHG Protocol \\
\hline & Method & IPCC 2013 & IPCC 2013 \\
\hline & Model & Proprietary spreadsheet tool [35] & Campus Carbon Calculator ${ }^{\mathrm{TM}}$ \\
\hline & Third-party verified & Yes & No \\
\hline \multirow{2}{*}{ Inventory boundaries } & Direct GHG emissions & Yes & Yes \\
\hline & Indirect GHG emissions & Yes & Yes \\
\hline \multirow{10}{*}{ GHG sources } & Stationary combustion & Yes & Yes \\
\hline & Direct transportation & Yes & Yes \\
\hline & Refrigerant gases leakage & Yes & No \\
\hline & Fertilizer application & No & Yes \\
\hline & Purchased electricity & Yes & Yes \\
\hline & Waste generated & Yes & Yes \\
\hline & Water consumption & Yes & No \\
\hline & Commuting & Yes & Yes \\
\hline & Wastewater & No & Yes \\
\hline & Paper & No & Yes \\
\hline
\end{tabular}


Table 3. GHG emissions and removals.

\begin{tabular}{|c|c|c|}
\hline \multirow{2}{*}{ Description } & \multicolumn{2}{|c|}{ GHG Emissions and Removals } \\
\hline & UNIGE & FIU \\
\hline $\begin{array}{l}\text { Source of GHG emissions under direct } \\
\text { control of the organization }\end{array}$ & $\begin{array}{ll} & \text { stationary combustion } \\
- & \text { university fleet } \\
- & \text { refrigerant gases leakage }\end{array}$ & $\begin{array}{ll} & \text { stationary combustion } \\
- & \text { university fleet } \\
- & \text { fertilizers }\end{array}$ \\
\hline $\begin{array}{l}\text { Indirect GHG emissions from } \\
\text { consumption of purchased energy }\end{array}$ & - $\quad$ purchased electricity & - $\quad$ purchased electricity \\
\hline Indirect emissions & $\begin{array}{l}\text { - } \quad \text { water consumption } \\
\text { - } \quad \text { commute generated in operations }\end{array}$ & $\begin{array}{ll}- & \text { waste generated in operations } \\
- & \text { commuting } \\
- & \text { wastewater } \\
- & \text { paper consumption }\end{array}$ \\
\hline
\end{tabular}

\subsubsection{Data Collection}

The characteristics of both universities and detailed information on data collecting methods and sources are reported in the following. UNIGE is one of the biggest Italian Universities, with about 32,000 students enrolled. It is divided among four cities (Genova, Savona, La Spezia, and Imperia), two campuses, and more than 50 buildings, all included in the inventory. FIU, with a student body of nearly 54,000, is among the top 10 largest universities in the US and has collectively graduated more than 200,000 alumni. Campuses included in GHG Inventory are Modesto Madique Campus, Biscayne Bay Campus, and Engineering Center. The summary of the average characteristics of UNIGE and FIU between 2013 and 2016 is given in Table 4.

Table 4. Characteristics of UNIGE and FIU (Data 2013-2016).

\begin{tabular}{ccc}
\hline Description & UNIGE & FIU \\
\hline Gross surface of building space & 364,430 & 863,496 \\
$\left(\mathrm{~m}^{2}\right)$ & Genova & Miami (Modesto Madique \\
Sites of university & Savona (Savona Campus) & Campus, Biscayne Bay Campus, \\
building/campus & La Spezia (“G. Marconi” Campus) & Engineering Center) \\
Total faculty & Imperia & 1485 \\
Total staff & 1275 & 6058 \\
Total student enrolment & 1406 & 54,062 \\
\hline
\end{tabular}

Collected data, listed in Table 5, were retrieved from direct measures or invoices in either case. If they were not available, emissions/removals of GHG were estimated following a conservative approach, as reported below. As a general rule, the choice of the method of quantification was based on the criteria of accuracy, consistency, and reproducibility of the calculations, as well as the minimization of the uncertainty associated with the same calculations. In particular, electricity and heat consumption derives from invoices. Water consumption derives from invoices or, if they are not available, is estimated through water meters. Waste produced by the university was estimated and calculated through on-field analyses [36]. Losses of refrigerants were estimated from the weight of refrigerants of the air conditioners. For each vehicle used by the personnel, specific fuel consumption was considered according to the type of car, while mileage was estimated from the odometer readings. About commuting, the number of trips and distance travelled by UNIGE staff and students from home was derived from a national survey promoted by the University of Milano Bicocca, whereas FIU promoted its own internal survey [37]. Vehicle percentage distribution and average distances calculated within the survey sample have been applied to whole university populations. The purchase data of fertilizers and paper derive from the university accounting software. Wastewater volume has been evaluated according to water meters. Data were collected on an annual basis and are adapted from the inventories of UNIGE [35] and FIU [38]. 
Table 5. Data collected for UNIGE and FIU (Data 2013-2016).

\begin{tabular}{|c|c|c|}
\hline Data & UNIGE & FIU \\
\hline \multicolumn{3}{|l|}{ Fuel use } \\
\hline Natural Gas $\left(\mathrm{m}^{3}\right)$ & $1,506,920$ & $1,853,219$ \\
\hline Natural Gas (kWh thermal) & $1,431,645$ & - \\
\hline Diesel (liters) & 152,953 & - \\
\hline LPG-Propane $\left(\mathrm{m}^{3}\right)$ & - & 108 \\
\hline \multicolumn{3}{|l|}{ University fleet } \\
\hline Gasoline (liters) & - & 484,516 \\
\hline Diesel (liters) & - & 223,722 \\
\hline Car $(\mathrm{km})$ & 138,365 & \\
\hline Refrigerants leakages (kg) & 20 & n.a. \\
\hline Fertilizers $(\mathrm{kg})$ & n.a. & 15,428 \\
\hline Electricity (kWh) & $20,934,208$ & $110,640,988$ \\
\hline Water (ton) & 209,139 & n.a. \\
\hline Waste disposed (ton) & 277 & 7212 \\
\hline \multicolumn{3}{|l|}{ Commuting } \\
\hline Faculty/Staff (km) & $9,002,781$ & $35,211,281$ by car \\
\hline Student $(\mathrm{km})$ & 792,285 & $\begin{array}{c}205,004,300 \text { by car } \\
2,647,033 \text { by bus }\end{array}$ \\
\hline Wastewater $\left(\mathrm{m}^{3}\right)$ & n.a. & 520,203 \\
\hline Paper (kg) & n.a. & 133,674 \\
\hline
\end{tabular}

Additional data on the national electricity mixes are reported in Table 6 to allow a proper analysis and understanding of the results. Data for UNIGE are retrieved from the annual declaration of TERNA [39], operator of the Italian high voltage transmission network, whereas data for FIU derive from the EIA report for Florida's State Profile and Energy Estimates [40].

Table 6. Electricity mixes applied to UNIGE and FIU energy consumption.

\begin{tabular}{ccc}
\hline Energy Sources & UNIGE & FIU \\
\hline Thermoelectric & $62.95 \%$ & $85.43 \%$ \\
Nuclear & - & $7.15 \%$ \\
Hydro & $21.54 \%$ & $0.04 \%$ \\
Wind & $5.42 \%$ & - \\
Biomass & - & $5.53 \%$ \\
Photovoltaic & $7.97 \%$ & - \\
Geothermal & $2.11 \%$ & - \\
Other renewables & - & $1.85 \%$ \\
\hline
\end{tabular}

\section{Results}

According to the data collected and presented above, the corresponding GHG emissions were calculated using specific emission factors (EF). The list of the EF used is shown in Appendix A. Results are expressed in tonnes of carbon dioxide equivalent $\left(\mathrm{tCO}_{2 \text {-eq }}\right)$.

Data employed in the calculation is the average for the last four years for which data is available (2013-2016) for both universities. For UNIGE, commuting refers only to 2015-2016. Figure 1 reports the average emissions distribution for both universities. 


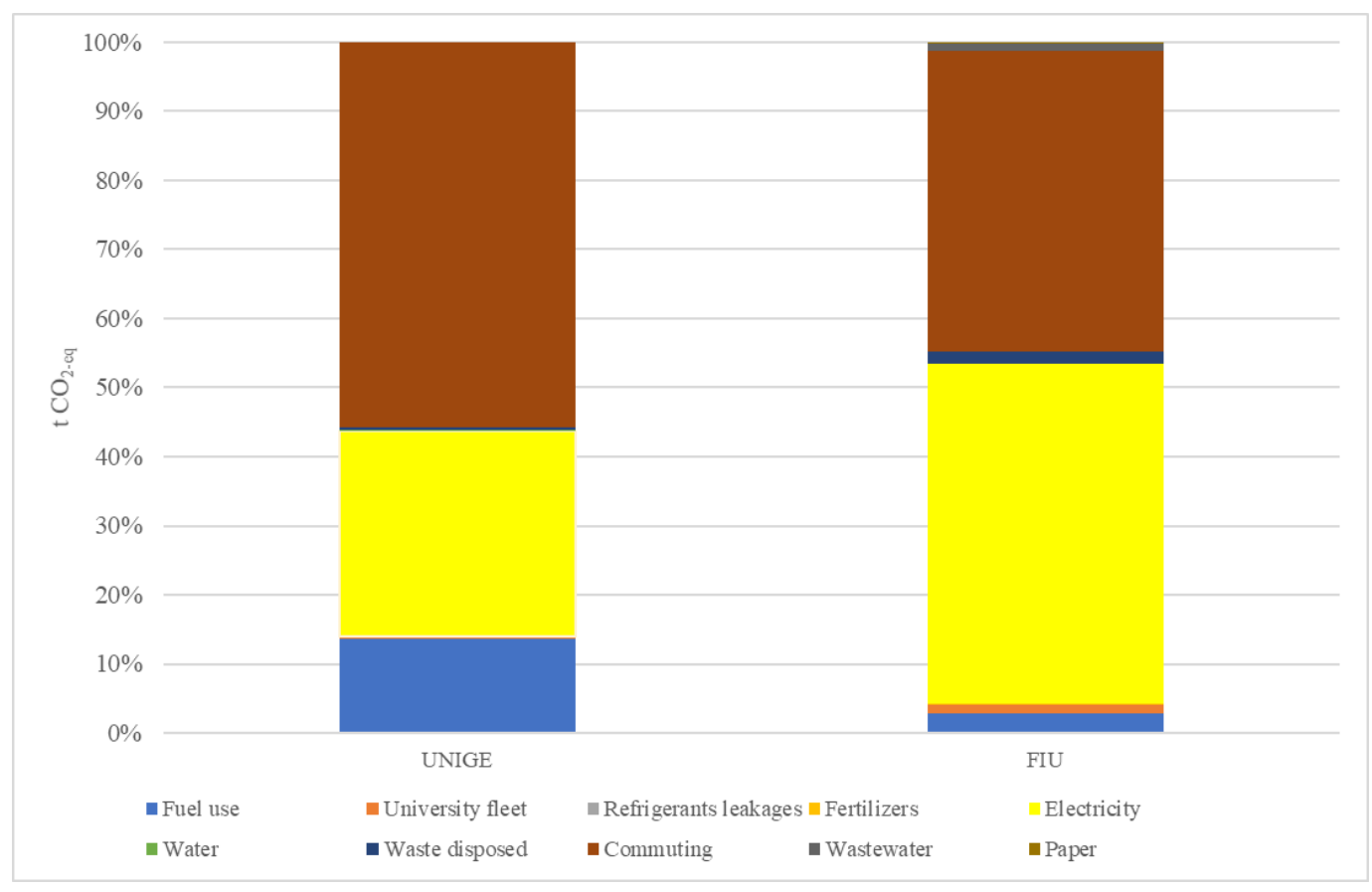

Figure 1. GHG emissions for UNIGE and FIU (Data 2013-2016).

The results clearly show that emissions are mainly due to electricity consumption and commuting, which together contribute to $90 \%$ of the total GHG emissions.

Fuel use averagely accounts for $13 \%$ for UNIGE and $3 \%$ for FIU, while the contribution of waste and university fleet, water and refrigerants leakages (only for UNIGE), fertilizers, and paper (only for FIU) are negligible if compared to the overall emissions of both universities.

Despite the negligible contribution of refrigerants leakages for UNIGE GHG emissions, the same assumption may not apply to FIU because of the widespread utilization of air conditioning. On the other side, the reduced percentage contribution of fuel-burning for heating is linked to the installation of heat pumping systems which cover most of the thermal energy demand of campuses.

As one of the purposes of this paper is to guide reliable greenhouse gas accounting of universities the results presented above have been normalized to the same basis to enhance comparability. Table 7 reports UNIGE and FIU GHG results, referred to the surface of buildings and the total number of faculty, staff, and students yearly attending each university.

Table 7. Comparison of GHG results for UNIGE and FIU (Data 2013-2016).

\begin{tabular}{ccccc}
\hline \multirow{2}{*}{ Sources } & \multicolumn{2}{c}{ UNIGE } & \multicolumn{2}{c}{ FIU } \\
\cline { 2 - 5 } & $\mathbf{t C O}_{\text {2-eq }} / \mathbf{m}^{\mathbf{2}}$ & $\mathbf{t C O} \mathbf{C}_{\text {2-eq }} /$ Person & $\mathbf{t C O}_{\text {2-eq }} / \mathbf{m}^{\mathbf{2}}$ & $\mathbf{t C O}_{\text {2-eq }} /$ Person \\
\hline Fuel use & 0.0104 & 0.1089 & 0.0042 & 0.0590 \\
University fleet & 0.0001 & 0.0006 & 0.0017 & 0.0232 \\
Refrigerants & 0.0001 & 0.0015 & - & - \\
leakages & - & - & 0.0004 & 0.0050 \\
Fertilizers & 0.0225 & 0.2364 & 0.0721 & 1.010 \\
Electricity & 0.0002 & 0.0019 & - & - \\
Water & 0.0003 & 0.0033 & 0.0026 & 0.0363 \\
Waste disposed & 0.0422 & 0.4433 & 0.0637 & 0.8924 \\
Commuting & - & - & 0.0014 & 0.0201 \\
Wastewater & - & - & 0.0003 & 0.0043 \\
Paper & 0.0758 & 0.7958 & 0.1445 & 2.0261 \\
\hline Total & & &
\end{tabular}


Comparing emissions between these universities requires caution. The methodologies used are comparable, together with accounting principles and emission factors used. However, buildings are in different countries, thus, the comparison may be influenced by local parameters such as the energy mix and travel distances. Moreover, despite their limited contribution to total GHG emissions, the two GHG inventories included different GHG sources: UNIGE includes refrigerants leakages and water, while FIU includes wastewater and paper. Therefore, due to these differences, the focus will not be on looking at the absolute numbers but comparing relative numbers.

Analyzing the results, the total impact of FIU is significatively higher than UNIGE and amounted to nearly $145 \mathrm{~kg}$ of $\mathrm{CO}_{2 \text {-eq }}$ per square meter compared to $76 \mathrm{~kg}$ of $\mathrm{CO}_{2 \text {-eq }}$ per square meter, and $2 \mathrm{tCO}_{2-\mathrm{eq}} /$ person, compared to less than $0.8 \mathrm{tCO}_{2 \text {-eq }}$ / person. Excluding other indirect emissions from the analysis, i.e., mainly commuting, which is outside the scope of the paper, UNIGE emits averagely about 12,000 tons of $\mathrm{CO}_{2 \text {-eq }}$ /year, corresponding to 0.03 tons of carbon dioxide equivalent per gross square meter, and FIU almost 68,000 tons of $\mathrm{CO}_{2 \text {-eq }}$ /year, corresponding to 0.08 tons of carbon dioxide equivalent per gross square meter. According to Ozawa-Meida, a medium-size university emits an average of 4,000 tons of $\mathrm{CO}_{2 \text {-eq }}$ /year for direct GHG emissions and indirect GHG emissions from consumption of purchased energy [10], while the minimum performance threshold of Campus annual adjusted net GHG emissions is 0.002 tons of carbon dioxide equivalent per gross square meter of floor area. Despite both UNIGE and FIU do not rate below this threshold, FIU GHGs are almost three times the emissions of UNIGE. Despite FIU has 1.7 times enrolled students and double building surface than UNIGE, FIU consumes more than five times the electricity of UNIGE. We could have modeled the electricity consumption using the same electricity mix to refine this number, but this would not have affected the outcome. The largest consumers of electricity at FIU are lighting, ventilation, and cooling. Therefore, it is clear that excessive all-year-round space cooling, thermal bridges in window frames and doors, 7/24/365 operated lighting, computer, and office equipment are responsible for most of GHGs emissions in buildings [15].

\section{Discussion}

\subsection{The Savona Campus of UNIGE}

The Savona Campus of UNIGE covers an area of about $60,000 \mathrm{~m}^{2}$ and is $2 \mathrm{~km}$ distant from the city center. Besides research laboratories of the University, the Campus also hosts SMEs research centres, as well as the CIMA Foundation-National Centre for Civil Protection on hydrogeological risk. The Savona Campus offers a set of different courses related to the Polytechnic School, the Medicine School, and the Social Sciences School, attended by approximately 1700 students.

The research activities at the Savona Campus are mainly dedicated to the sustainable energy sector. In this field, the "Energia 2020" project of the University of Genoa focused on developing new concepts of Sustainable Energy (renewable energy, energy-saving, and reduction of $\mathrm{CO}_{2}$ emissions) and Smart City [41]. The project-developed thanks to full public financing - has foreseen the installation of innovative energy systems within the Savona Campus to reduce operating costs, $\mathrm{CO}_{2}$ emissions and, at the same time, creating a comfortable working environment for the Campus users.

Three different subprojects contributed to the definition of the "Energia 2020" project: the Smart Polygeneration Microgrid (SPM); the energy efficiency measures (EEM); and the Smart Energy Building (SEB). In particular, the SEB consists of a sustainable smart building linked to the Campus microgrid, characterized by energy efficiency measures and equipped with renewable energy plants [42]. The construction of the building-in operation since February 2017-has been funded by the Italian Ministry of the Environment and Protection of Land and Sea with $3 \mathrm{M} €$. The building is a two-level fabricate which covers a total area of $1000 \mathrm{~m}^{2}$ and it is heated and cooled only by a geothermal plant and electrically powered by photovoltaic panels and storages, all built inside the building itself. The SEB is also equipped with a BMS (Building Management System) interacting in real-time with the 
Energy Management System of the microgrid (Figure 2), to which the building is connected as a prosumer. First of its kind in Italy, this feature characterizes the SEB as a "Smart City" urban infrastructure.

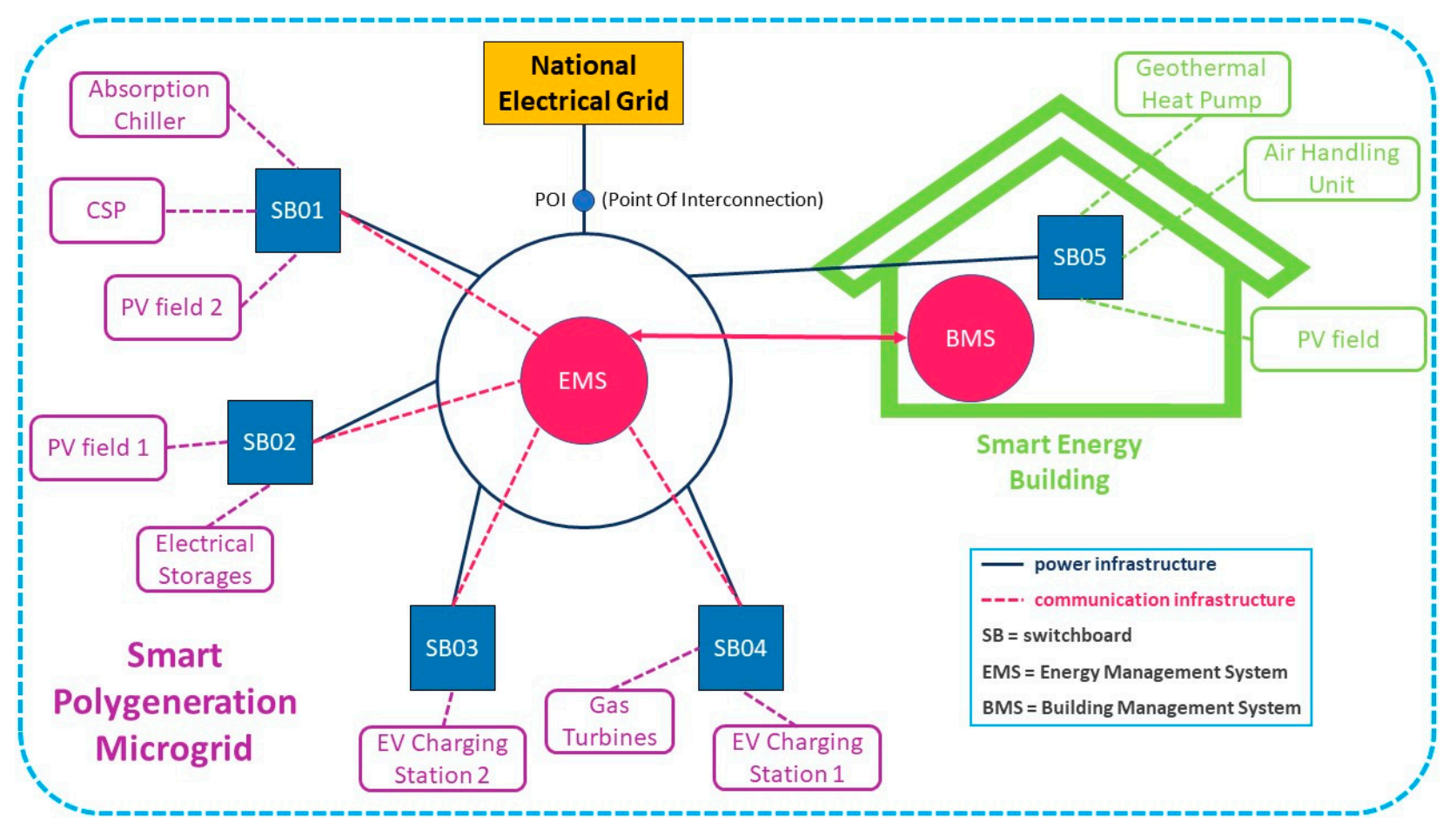

Figure 2. SEB and SPM power and communication connections (Savona Campus).

In particular, the SEB is characterized by the presence of:

1. High-performance thermal insulation materials for building applications

2. Geothermal heat pump ( $45 \mathrm{kWth}, 8$ probes reaching $100 \mathrm{~m}$ depth)

3. Solar Thermal Collectors on the rooftop

4. Controlled mechanical ventilation plant, air handling unit

5. Domestic hot water heat pump

6. Photovoltaic field $(21 \mathrm{kWp})$ on the roof

7. Extremely low consumption led lamps

8. Rainwater collection system

9. Ventilated facades

10. Technological gym (bikes, tapis roulant, and elliptical machines that convert "human energy" into electrical energy).

The Smart Polygeneration Microgrid and the Smart Energy Building allow the University of Genoa to reduce $\mathrm{CO}_{2}$ emissions deriving from primary energy use on the campus. Despite the energy demand increased by 130 MWh per year owing to the construction of the new building, the balance of the energy consumption and the related GHG emissions of the Savona Campus has witnessed an overall reduction of about 24 toe/y of primary energy consumptions, avoiding the emission of about $86 \mathrm{tCO}_{2} / \mathrm{y}$ [41].

\subsection{The Paul L. Cejas School of Architecture Building of FIU}

The Paul L. Cejas School of Architecture (PCA) Building-named after the former Ambassador to Belgium and South Florida-is located on the north-western side of the Florida International University Campus. The facility - designed by architect Bernard Tschumi-covers a total area of $9246 \mathrm{~m}^{2}$ and features a multi-level studio in the north area of PCA with space for 375 students. The layout of the building sees two three-story wings arranged around a central courtyard surrounded by two 3-story lecture, studio, 
and exhibition buildings. The building's mass is predominantly constructed out of simple structural pre-cast concrete without added insulation.

In line with the main goals of the ZEB project, the PCA has been equipped with a wireless smart-sensor infrastructure system compatible with the existing Metasys ${ }^{\circledR}$ building management system from Johnson Controls. The system allows the collection of real-time data and the identification and comparison of different strategies for the reduction of operational building energy consumption and the related GHG emissions and the operating costs in the long term while improving thermal comfort in the building.

Afterward, the water and energy consumption of the building has been assessed by an interdisciplinary research team employing 3-D modeling tools. Thanks to the definition of this baseline consumption, multiple "what-if" scenarios-based on passive and active water and energy-saving implementation strategies-have been tested to evaluate the potential improvements and reductions in the environmental footprint. According to the targets of the AIA 2030 Agenda [43] and U.S. Federal NET-ZEB 2018-2020 criteria, the Paul L. Cejas NET-ZEB Master Plan defined the implementation of conservation strategies and the onsite energy production from renewable sources. The general roadmap for the final achievement of the ZEB status for the PCA has been made of two phases:

The implementation of conservation (passive means for the minimization of heat transfer into the building) and energy efficiency measures (the control of HVAC and lighting through a smart integrated sensor infrastructure) for the reduction of energy and water consumption;

1. The achievement for the PCA of the required net balance for NET-ZEBs with the onsite generation of renewable energy or the purchase of energy supply options for green credits.

2. The PCA building has been able to reduce by 30 percent the building operation bills and GHGs using the implementation of the above said energy and water efficiency measures.

\subsection{Design Versus Retrofitting and Other GHG Reduction Measures}

According to data reported in Sctions 4.1.1, the SEB built in the Savona Campus allows the avoidance of $0.086 \mathrm{tCO}_{2} / \mathrm{m}^{2}$ per year. Considering the average emission of $0.03 \mathrm{tCO}_{2} / \mathrm{m}^{2}$ for UNIGE Scope $1+2$, this leads to an overall negative GHG balance showing how ZEBs has the potential to reduce the overall emissions of UNIGE or to compensate the dismantling of old building and construction of new ones on a short time period. Thus, this result may allow maintaining the ZEB definition also according to regulations considering plug load and/or embodied energy within the life cycle stages considered.

On the other side, the retrofitting operated by FIU showed a GHG reduction of only $30 \%$ - then not competitive with the results of a ZEB - but, compared to the construction of new ZEBs, it avoids the emissions related to dismantling processes, reduces those generated by the construction phase and requires a lower economic investment.

As both EU and US regulations set minimum requirements for the energy efficiency of ZEBs, also different applied measures can be discussed. Despite the fact that aggregated data are given for the period 2013-2016, it must be noted that different strategies applied by UNIGE starting from 2014 offered a significant reduction in the average energy demand of years 2014-2016 with respect to the year 2013. On the one side, the implementation of a real-time monitoring system for energy consumption in the Genoa campus and the partial switch from traditional lighting to LED or other energy-saving lighting allowed a $22 \%$ reduction of the electricity demand. According to an internal analysis, the Polytechnic of Turin obtained an $85 \%$ reduction in energy demand for lighting with the installation of LED lighting [44]. On the other side, the construction of a combined heat and power (CHP) system - made of two micro-turbines-in the Savona campus led to a reduction of $6.5 \%$ in the electricity purchased from the grid despite the increase in energy consumption. The effectiveness of these measures can be evaluated by analyzing 
the GHG emissions linked with the overall energy consumption in terms of electricity demand and thermal energy derived from diesel or natural gas. In 2013, the sole Genoa campus emitted $0.322 \mathrm{~kg} \mathrm{CO} 2 \mathrm{eq} / \mathrm{kWh}$ of total energy against the $0.329 \mathrm{~kg} \mathrm{CO} 2 \mathrm{eq} / \mathrm{kWh}$ of the Savona campus. The abovesaid efficiency measures allowed, in 2016, both campuses to reduce their indicator respectively to $0.297 \mathrm{~kg} \mathrm{CO}_{2} \mathrm{eq} / \mathrm{kWh}$ (about $8 \%$ reduction) for Genoa and $0.254 \mathrm{~kg} \mathrm{CO}_{2} \mathrm{eq} / \mathrm{kWh}$ for Savona (almost $23 \%$ reduction). Consequently, the Savona campus switched from a 2\% worse performance in 2013 to a 15\% better one in 2016 rather than the Genoa campus. It is clear how, despite both measures allowing a significant potential reduction in energy demand and GHG emissions, cogeneration seems to offer better results and opportunities for University strategies on the pathway to make buildings and campus facilities benchmarked and carbon-neutral. Furthermore, in terms of surface indicator, the 2013-2016 average value of Scope $1+2$ for the Savona campus results in $0.029 \mathrm{tCO}_{2 \text {-eq }} / \mathrm{m}^{2}$ against the $0.033 \mathrm{tCO}_{2 \text {-eq }} / \mathrm{m}^{2}$ of the whole UNIGE (about $13 \%$ lower).

According to an analysis of electricity consumption by Italian Universities defines an average consumption of 500-550 kwh/student [44]. Despite the energy efficiency measures applied by UNIGE, its energy consumption still results in about $600 \mathrm{kWh} /$ student showing a gap for potential improvement. While considering the different climate regions, the consumption of above $2000 \mathrm{kWh} /$ student measured for FIU also suggests the need for additional efficiency measures.

In general, UNIGE indicators for GHG emissions result similar to other Italian Universities: the University “La Sapienza” assessed GHG emissions for $0.145 \mathrm{tCO}_{2 \text { eq }} /$ person and $0.038 \mathrm{tCO}_{2 \text { eq }} / \mathrm{m}^{2}$ [45]; the Polytechnic of Milan assessed GHG emissions for $0.386 \mathrm{tCO}_{2 \text { eq }} /$ person [46]; and the University of Milan "Bicocca" assessed GHG emissions for $0.330 \mathrm{tCO}_{2 \text { eq }} /$ person and $0.043 \mathrm{tCO}_{2 \text { eq }} / \mathrm{m}^{2}$ [47]. According to these results, the Polytechnic of Milan is also planning to reduce by about $12 \%$ its GHG emissions by 2030, applying the following measures: installation of a tri-generation system and a photovoltaic plant, switch to LED lighting, and energy requalification of buildings.

Energy efficiency can also be achieved with different retrofitting strategies. A case study of building retrofitting through the installation of a vertical greening system developed in the city of Genoa showed an over $50 \%$ reduction in energy consumption for air conditioning and building operation in the summer period (June-September) [48]. Therefore, the study shows how similar solutions might be applied to UNIGE university buildings obtaining GHG reductions similar to FIU.

In general, a significant reduction in greenhouse gas (GHG) emissions can be obtained by implementing energy efficiency measures in buildings: in order to guarantee the overall sustainability of these measures, new projects for a sustainable design and the installation of energy production systems should be based on and tested through both economic and environmental criteria [49-51].

If energy efficiency measures are applied through retrofitting, other indirect measures may be applied to aim at net-zero GHG emissions - or at least at reducing them-for building operation. An energy-related solution is that of Renewable Energy Certificates (RECs) purchase, used to address indirect GHG emissions associated with purchased electricity (Scope 2 emissions) by verifying the use of zero- or low-emissions renewable sources of electricity. Coupling energy efficiency measures and RECs purchase may be a very competitive and viable solution for GHG emission reduction, as electricity consumption represents about $68 \%$ of Scope $1+2$ emissions for UNIGE and even $92 \%$ for FIU. It must be noted that for RECs to be effective, an actual increase in renewable energy sources has to be sought by the energy producers to guarantee an emission reduction also at a global scale instead of just creating a burden-shifting mechanism.

Another indirect measure may be carbon offsetting, i.e., a mechanism that allows compensating for one's emissions by funding an equivalent carbon dioxide saving at additional, external projects. The project has to be additional; the resulting emissions reductions have to be real, permanent, and verified; and credits (i.e., offsets) issued for verified emissions reductions must be enforceable. Offsets are subtracted from organizational emissions 
(Scope $1+2+3$ ) to determine net organizational emissions. Unlike RECs purchase, carbon offsetting can then allow a target of net-zero GHG emissions.

\section{Conclusions}

The present paper shows research projects promoting environmental sustainability of University campuses operations at the international level. GHG accounting methods and operational strategies adopted by the University of Genoa, Italy, and at the Florida International University in Miami, USA, are compared on the pathway to make buildings and campus facilities benchmarked and carbon-neutral in the near future.

Both the Universities assess their GHG emissions inventory using standards that, for the aim of the present analysis, can be considered comparable. Comparing the results of the last GHG inventory available, FIU Scope $1+2$ GHGs are more than three times the UNIGE emissions per person and 2.4 higher per square meter. Despite FIU has 1.7 times enrolled students and double building surface than UNIGE, FIU consumes more than five times the electricity of UNIGE. Purchased electricity has the highest contribution for FIU—about $50 \%$ - and accounts for almost $30 \%$ for UNIGE.

To present research aimed at making buildings and campus facilities carbon-neutral, two case studies were discussed: the Smart Energy Building in the Savona Campus of the University of Genoa and the Paul L. Cejas School of Architecture Building of the Florida International University. Operational strategies, including energy efficiency and energy generation, aiming at reducing the GHG emissions in both the buildings show a high potential towards climate neutrality of the buildings.

University campuses can thus be considered as Living Labs, opening up their buildings as a testbed for creating new, sustainable processes and infrastructure such as performing researches that address the challenges of climate change.

Author Contributions: Conceptualization, A.D.B. and T.S.; methodology, M.G.; writing—original draft preparation, A.D.B. and T.S.; writing-review and editing, L.M. All authors have read and agreed to the published version of the manuscript.

Funding: This research received no external funding.

Institutional Review Board Statement: Not applicable.

Informed Consent Statement: Not applicable.

Data Availability Statement: Not applicable.

Conflicts of Interest: The authors declare no conflict of interest. 


\section{Appendix A}

The list of main emission factors is reported in the table below.

Table A1. List of emission factors.

\begin{tabular}{|c|c|c|c|c|}
\hline Data & FIU & U.M. & UNIGE & U.M. \\
\hline Natural gas & 53.167 & $\mathrm{~kg} \mathrm{CO}$-eq $/ \mathrm{MMBtu}$ & 1.955 & $\mathrm{~kg} \mathrm{CO}_{2-\mathrm{eq}} / \mathrm{Sm}^{3}$ \\
\hline Natural gas & - & $x^{-2-1}$ & 0.241 & $\mathrm{~kg} \mathrm{CO}_{2 \text {-eq }} / \mathrm{kWh}$ th \\
\hline LPG (Propane) & 5.221 & $\mathrm{~kg} \mathrm{CO}_{2 \text {-eq }} /$ gallon & 3.024 & $\mathrm{~kg} \mathrm{CO}_{2 \text {-eq }} / \mathrm{kg}$ \\
\hline Diesel & - & - & 3.155 & $\mathrm{~kg} \mathrm{CO}_{2-\mathrm{eq}} / \mathrm{kg}$ \\
\hline Gasoline fleet & 8.824 & $\mathrm{~kg} \mathrm{CO}_{2 \text {-eq }} /$ gallon & - & - \\
\hline Diesel fleet & 10.256 & $\mathrm{~kg} \mathrm{CO}_{2 \text {-eq }} /$ gallon & 0.148 & $\mathrm{~kg} \mathrm{CO}_{2-\mathrm{eq}} / \mathrm{km}$ \\
\hline B5 fleet & 9.715 & $\mathrm{~kg} \mathrm{CO}_{2 \text {-eq } / \text { gallon }}$ & - & -1 \\
\hline B20 fleet & 8.111 & $\mathrm{~kg} \mathrm{CO}_{2 \text {-eq }} /$ gallon & - & - \\
\hline Refrigerant gas R-422D & - & - & 2.729 & $\mathrm{~kg} \mathrm{CO}_{2 \text {-eq }} / \mathrm{kg}$ \\
\hline Refrigerant gas R-410A & - & - & 2.088 & $\mathrm{~kg} \mathrm{CO}_{2 \text {-eq }} / \mathrm{kg}$ \\
\hline Refrigerant gas R-407C & - & - & 1.774 & $\mathrm{~kg} \mathrm{CO}_{2 \text {-eq }} / \mathrm{kg}$ \\
\hline Synthetic fertilizer & 4.194 & $\mathrm{kgCO}_{2 \text {-eq }} / \mathrm{lb} \mathrm{N}$ & - & -1 \\
\hline Organic fertilizer & 4.141 & $\mathrm{kgCO}_{2 \text {-eq }} / \mathrm{lb} \mathrm{N}$ & - & - \\
\hline Electricity & 0.562 & $\mathrm{kgCO}_{2 \text {-eq }} / \mathrm{kWh}$ & 0.375 & $\mathrm{~kg} \mathrm{CO}_{2-\mathrm{eq}} / \mathrm{kWh}$ \\
\hline Automobile & 0.365 & $\mathrm{~kg} \mathrm{CO}_{2 \text {-eq }} / \mathrm{mile}$ & 0.134 & $\mathrm{kgCO}_{2 \text {-eq }} / \mathrm{pkm}$ \\
\hline Bus & 0.321 & $\mathrm{~kg} \mathrm{CO}_{2 \text {-eq }} / \mathrm{mile}$ & 0.014 & $\mathrm{~kg} \mathrm{CO}$ 2-eq $/ \mathrm{pkm}$ \\
\hline Ferry boat & - & - & 0.530 & $\mathrm{kgCO}_{2 \text {-eq }} / \mathrm{pkm}$ \\
\hline Subway & - & - & 0.040 & $\mathrm{kgCO}_{2-\mathrm{eq}} / \mathrm{pkm}$ \\
\hline Motorcycle & - & - & 0.075 & $\mathrm{~kg} \mathrm{CO}_{2-\mathrm{eq}} / \mathrm{pkm}$ \\
\hline Train & - & - & 0.040 & $\mathrm{kgCO}_{2-\mathrm{eq}} / \mathrm{pkm}$ \\
\hline Short haul flight & - & - & 0.131 & $\mathrm{kgCO}_{2-\mathrm{eq}} / \mathrm{pkm}$ \\
\hline Medium haul flight & - & - & 0.126 & $\mathrm{kgCO}_{2-\mathrm{eq}} / \mathrm{pkm}$ \\
\hline Long haul flight & - & - & 0.111 & $\mathrm{kgCO}_{2-\mathrm{eq}} / \mathrm{pkm}$ \\
\hline Landfilled waste & 0.310 & $\mathrm{~kg} \mathrm{CO}_{2 \text {-eq }} / \mathrm{kg}$ & 0.623 & $\mathrm{~kg} \mathrm{CO}_{2 \text {-eq }} / \mathrm{kg}$ \\
\hline Incinerated waste & - & -10 & 0.478 & $\mathrm{~kg} \mathrm{CO}_{2 \text {-eq }} / \mathrm{kg}$ \\
\hline Water & - & - & 0.318 & $\mathrm{~kg} \mathrm{CO} 2$-eq $/ \mathrm{m}^{3}$ \\
\hline Wastewater & 0.009 & $\mathrm{~kg} \mathrm{CO}_{2 \text {-eq }} /$ gallon & - & - \\
\hline Paper & 1.068 & $\mathrm{kgCO}_{2 \text {-eq }} / \mathrm{lb}$ & - & - \\
\hline
\end{tabular}

\section{References}

1. IEA. Energy Efficiency 2019; IEA: Paris, France, 2019.

2. Rogelj, J.; den Elzen, M.; Höhne, N.; Fransen, T.; Fekete, H.; Winkler, H.; Schaeffer, R.; Sha, F.; Riahi, K.; Meinshausen, M. Paris Agreement Climate Proposals Need a Boost to Keep Warming Well below $2{ }^{\circ} \mathrm{C}$. Nature 2016, 534, 631-639. [CrossRef]

3. Department for Communities and Local Government. Definition of Zero Carbon Homes and Non-Domestic Buildings: Consultation; Department for Communities and Local Government: London, UK, 2008; ISBN 978-1-4098-0934-0.

4. Amicarelli, V.; Bux, C.; Lagioia, G.; Gallucci, T. Energy Efficiency Policies in Non-Residential Buildings: The Case of the University of Bari Aldo Moro. Amfiteatru Econ. 2019, 21, 845. [CrossRef]

5. Advanced Energy Design Guide for K-12 School Buildings: Achieving Zero Energy; ASHRAE: Atlanta, GA, USA, 2018; ISBN 978-1-939200-93-8.

6. Save, P.; Terim Cavka, B.; Froese, T. Evaluation and Lessons Learned from a Campus as a Living Lab Program to Promote Sustainable Practices. Sustainability 2021, 13, 1739. [CrossRef]

7. Tonietto, R.; O'Brien, L.; Van Haitsma, C.; Su, C.; Blankertz, N.; Mosiniak, H.G.S.; Short, C.; Dawson, H.A. Toward a Carbon Neutral Campus: A Scalable Approach to Estimate Carbon Storage and Biosequestration, an Example from University of Michigan. Int. J. Sustain. High. Educ. 2021. ahead-of-print. [CrossRef]

8. Shea, R.P.; Worsham, M.O.; Chiasson, A.D.; Kelly Kissock, J.; McCall, B.J. A Lifecycle Cost Analysis of Transitioning to a Fully-Electrified, Renewably Powered, and Carbon-Neutral Campus at the University of Dayton. Sustain. Energy Technol. Assess. 2020, 37, 100576. [CrossRef]

9. Spiegelhalter, T. Achieving the net-zero-energy-buildings "2020 and 2030 targets" with the support of parametric 3-D/4-D BIM design tools. J. Green Build. 2012, 7, 74-86. [CrossRef]

10. Ozawa-Meida, L.; Brockway, P.; Letten, K.; Davies, J.; Fleming, P. Measuring Carbon Performance in a UK University through a Consumption-Based Carbon Footprint: De Montfort University Case Study. J. Clean. Prod. 2013, 56, 185-198. [CrossRef] 
11. Ferrer-Balas, D.; Lozano, R.; Huisingh, D.; Buckland, H.; Ysern, P.; Zilahy, G. Going beyond the Rhetoric: System-Wide Changes in Universities for Sustainable Societies. J. Clean. Prod. 2010, 18, 607-610. [CrossRef]

12. Klein-Banai, C.; Theis, T.L. An Urban University's Ecological Footprint and the Effect of Climate Change. Ecol. Indic. 2011, 11, 857-860. [CrossRef]

13. Venetoulis, J. Assessing the Ecological Impact of a University: The Ecological Footprint for the University of Redlands. Int. J. Sustain. High. Educ. 2001, 2, 180-197. [CrossRef]

14. Song, G.; Che, L.; Zhang, S. Carbon Footprint of a Scientific Publication: A Case Study at Dalian University of Technology, China. Ecol. Indic. 2016, 60, 275-282. [CrossRef]

15. Spiegelhalter, T. Energy-Efficiency Retrofitting and Transformation of the FIU-College of Architecture + The Arts into a Net-ZeroEnergy-Building by 2018. Energy Procedia 2014, 57, 1922-1930. [CrossRef]

16. Caserini, S.; Baglione, P.; Cottafava, D.; Gallo, M.; Laio, F.; Magatti, G.; Maggi, V.; Maugeri, M.; Moreschi, L. Fattori di emissione di $\mathrm{CO}_{2}$ per consumi energetici e trasporti per gli inventari di gas serra degli atenei italiani. IdA 2019, 6, 43-59. [CrossRef]

17. WRI/WBCSD Global Protocol for Community-Scale Greenhouse Gas Emission Inventories; World Resources Institute: Washington, DC, USA, 2014

18. ISO UNI EN ISO 14064-1-Greenhouse Gases_Part 1: Specification with Guidance at the Organization Level for Quantification and Reporting of Greenhouse Gas Emissions and Removals; International Organisation for Standardisation: Geneva, Switzerland, 2006.

19. ISO UNI EN ISO 14040:2006 Environmental Management_Life Cycle Assessment_Principles and Framework; International Organisation for Standardisation: Geneva, Switzerland, 2021.

20. Gallo, M.; Arcioni, L.; Leonardi, D.; Moreschi, L.; Del Borghi, A. GHG Accounting for Sustainable Mega-Events: How Lessons Learnt during the Milan Expo 2015 World Fair Could Lead to Less Carbon-Intensive Future Mega-Events. Sustain. Prod. Consum. 2020, 22, 88-109. [CrossRef]

21. EU Directive 2010/31/EU of the European Parliament and of the Council of 19 May 2010 on the Energy Performance of Buildings; European Commission: Brussels, Belgium, 2010.

22. Zhang, J.; Zhou, N.; Hinge, A.; Feng, W. Zero-Energy Buildings-An Overview of Terminology and Policies in Leading World Regions. Available online: https://www.eceee.org/library/conference_proceedings/eceee_Summer_Studies/2015/6-policiesand-programmes-towards-a-zero-energy-building-stock/zero-energy-buildings-an-overview-of-terminology-and-policiesin-leading-world-regions / (accessed on 9 July 2021).

23. EU Directive 2012/27/EU of the European Parliament and of the Council of 25 October 2012 on Energy Efficiency, Amending Directives 2009/125/EC and 2010/30/EU and Repealing Directives 2004/8/EC and 2006/32/EC; European Commission: Brussels, Belgium, 2012.

24. EC Directive 2009/28/EC of the European Parliament and of the Council of 23 April 2009 on the Promotion of the Use of Energy from Renewable Sources and Amending and Subsequently Repealing Directives 2001/77/EC and 2003/30/EC; European Commission: Brussels, Belgium, 2009.

25. EC Directive 2009/125/EC of the European Parliament and of the Council of 21 October 2009 Establishing a Framezork for the Setting of Ecodesign Requirements for Energy-Related Products; European Commission: Brussels, Belgium, 2009.

26. EU Directive 2010/30/EU of the European Parliament and of the Council of 19 May 2010 on the Indication by Labelling and Standard Product Information of the Consumption of Energy and Other Resources by Energy-Related Products; European Commission: Brussels, Belgium, 2010.

27. EC Communication From The Commission to the European Parliament, The European Council, The Council, The Euro-pean Economic and Social Committee and The Committee of The Regions-The European Green Deal; European Commission: Brussels, Belgium, 2019.

28. Final Report 2019: EC Comprehensive Study of Building Energy Renovation Activities and the Uptake of Nearly Zero-Energy Buildings in the EU; European Commission: Brussels, Belgium, 2020.

29. Toleikyte, A.; Kranzl, L.; Bointner, R.; Bean, F.; Cipriano, J.; De Groote, M.; Hermelink, A.; Klinski, M.; Kretschmer, D.; Lapilonne, B.; et al. Zebra 2020-Nearly Zero-Energy Building Strategy 2020; Strategies for a Nearly Zero-Energy Building Market Transition in the European Union, 2016. Available online: https:/ / apo.org.au/node/209211 (accessed on 9 July 2021).

30. U.S. Department of Energy Executive Order (EO) 13514. Federal Leadership in Environmental, Energy, and Economic Performance; U.S. Department of Energy: Washington, DC, USA, 2009.

31. U.S. Department of Energy A Common Definition for Zero Energy Buildings; U.S. Department of Energy: Washington, DC, USA, 2015.

32. Campus Carbon Calculator. Available online: https://www.unh.edu/sustainability/research/campus-calculator-tools (accessed on 9 July 2021).

33. Wernet, G.; Bauer, C.; Steubing, B.; Reinhard, J.; Moreno-Ruiz, E.; Weidema, B. The Ecoinvent Database Version 3 (Part I): Overview and Methodology. Int. J. Life Cycle Assess. 2016, 21, 1218-1230. [CrossRef]

34. Climate Change 2013-The Physical Science Basis: Working Group I Contribution to the Fifth Assessment Report of the Intergovernmental Panel on Climate Change; Intergovernmental Panel on Climate Change (Ed.) Cambridge University Press: Cambridge, UK, 2014; ISBN 978-1-107-41532-4.

35. CESISP, Centre for the Development of Product Sustainability, University of Genoa. Proprietary Spreadsheet Tool—Campus Carbon Footprint. Available online: https:/ / unigesostenibile.unige.it/en/carbon_footprint (accessed on 9 July 2021).

36. Gallo, M.; Marotta, V.; Magrassi, F.; Taramasso, A.C.; Del Borghi, A. University Campus Waste Prevention and Reduction: A Circular-Economy Approach. Econ. Policy Energy Environ. 2017, 235-252. [CrossRef] 
37. University of Milano Bicocca 1^Rapporto Nazionale La Sharing Mobility in Italia: Numeri, Fatti E Potenzialita'; University of Milano Bicocca: Milan, Italy, 2016.

38. Annual Progress Evaluation for Florida International University. Available online: https://reporting.secondnature.org/ape/apepublic!213 (accessed on 9 July 2021).

39. TERNA Confronti Internazionali; TERNA: Rome, Italy, 2015.

40. EIA FLORIDA State Profile and Energy Estimates. Available online: https://www.eia.gov/state/?sid=FL\#tabs-1 (accessed on 9 July 2021).

41. Bracco, S.; Delfino, F.; Pampararo, F.; Robba, M.; Rossi, M. A Pilot Facility for Analysis and Simulation of Smart Microgrids Feeding Smart Buildings. Renew. Sustain. Energy Rev. 2016, 58, 1247-1255. [CrossRef]

42. Bracco, S.; Delfino, F.; Pampararo, F.; Robba, M.; Rossi, M. A Dynamic Optimization-Based Architecture for Polygeneration Microgrids with Tri-Generation, Renewables, Storage Systems and Electrical Vehicles. Energy Convers. Manag. 2015, 96, 511-520. [CrossRef]

43. AIA Agenda for Carbon Neutrality of Buildings, Cities and Infrastructures; AIA: Washington, DC, USA, 2015.

44. Poggio, A. La Gestione Efficiente Dell'energia per La Decarbonizzazione Degli Atenei Italiani; Polytechnic of Turin: Turin, Italy, 2021.

45. De Santoli, L.; Lettina, F.; Manes, F.; Sebastiani, A.; Sferra, A. 2020 Prima e Dopo: L'impronta Di Carbonio Della Sapienza Di Roma; University "La Sapienza": Rome, Italy, 2021.

46. Caserini, S.; Baglione, P.; Perotto, E.; Messori, G.; Tolentino, S.; Beria, P.; Bovera, F.; Komaie, R.; Motta, M. L'impatto Del Covid-19 Sulle Emissioni Di $\mathrm{CO}_{2}$ Del Politecnico Di Milano: Metodologie e Risultati; Polytechnic of Milan: Milan, Italy, 2021.

47. Acciarri, M.; Magatti, G.; Maggi, V. Impatto Del Covid-19 Sulle Emissioni Dell'Università Di Milano-Bicocca; University of Milan "Bicocca": Milan, Italy, 2021.

48. Perini, K.; Magrassi, F.; Giachetta, A.; Moreschi, L.; Gallo, M.; Del Borghi, A. Environmental Sustainability of Building Retrofit through Vertical Greening Systems: A Life-Cycle Approach. Sustainability 2021, 13, 4886. [CrossRef]

49. Magrassi, F.; Del Borghi, A.; Gallo, M.; Strazza, C.; Robba, M. Optimal Planning of Sustainable Buildings: Integration of Life Cycle Assessment and Optimization in a Decision Support System (DSS). Energies 2016, 9, 490. [CrossRef]

50. Reverberi, A. Optimal Design of Cogeneration Systems in Industrial Plants Combined with District Heating/Cooling and Underground Thermal Energy Storage. Energies 2011, 4, 2151-2165. [CrossRef]

51. Magrassi, F.; Rocco, E.; Barberis, S.; Gallo, M.; Del Borghi, A. Hybrid Solar Power System versus Photovoltaic Plant: A Comparative Analysis through a Life Cycle Approach. Renew. Energy 2019, 130, 290-304. [CrossRef] 